\title{
INFLUENCE OF MODELLING CHOICES ON THE RESULTS OF LANDFILL ODOUR DISPERSION
}

\author{
Francesca Tagliaferri, Marzio Invernizzi, Selena Sironi and Laura Capelli *
}

Politecnico di Milano, Department of Chemistry, Materials and Chemical Engineering "Giulio Natta", P.za Leonardo da Vinci 32, 20133 Milano, Italy

Article Info:
Received:
27 November 2019
Revised:
24 March 2020
Accepted:
25 March 2020
Available online:
26 July 2020
Keywords:
Odour emissions
Olfactometry
CALPUFF
Dispersion model
Odour sampling
Area source

Article Info:

27 November 2019

25 March 2020

Available online:

6 July 2020

Keywords:

Odour emissions

CALPUFF

Odour sampling

Area source

\begin{abstract}
Landfills are an important source of odour pollution, potentially causing nuisance to adjacent populations. The most commonly used odour impact assessment for this type of plants usually involves a combination of dynamic olfactometry with dispersion modelling. Despite the advantages associated with the use of dispersion models, there are still some important issues related to their uncertainty. The dispersion model requires the Odour Emission Rate (OER) as input, expressed as units of odour emitted per unit time. Source term characterization and the estimation of the OER are typically the most important steps in the model's implementation, accounting for the highest contribution to the overall uncertainty. Another important element of uncertainty when modelling emissions from landfill surfaces is the geometrical implementation of the emission source in the dispersion model. This entails the definition of the initial dimensions of the emission, which is critical in the case of large area sources. This paper discusses issues related to uncertainty in the use of dispersion models for the evaluation of landfill odour impacts, particularly focusing on the estimation of the OER and the emission's initial vertical dimension. This study shows that modelling choices may lead to a variance in the resulting modelled odour concentrations at receptors differing by up to a factor 3 . This variability should not cause distrust in the method, but rather indicates the importance of having odour dispersion modelling studies carried out by experts with deep knowledge of the physical-chemical mechanisms underlying atmospheric emissions.
\end{abstract}

\section{INTRODUCTION}

In recent decades, public awareness of air quality issues has increased considerably. This led to the inclusion of odours, which can negatively affect human well-being without necessarily having an adverse effect on health (Sucker et al., 2001; Zhao et al., 2015), among the atmospheric pollutants subject to control and regulation in many countries (Brancher et al., 2017). Indeed, due to the fact that residential areas are often very close to industrial activities, odours are currently a major cause of complaints to local authorities (Henshaw et al., 2006; Marchand et al., 2013). In many cases odour complaints become the limiting factor for the operation of existing plants or for the realization of new ones. This is particularly true for plants involved in the treatment and disposal of waste, which are a common source of odour emissions and of consequent concerns for adjacent populations (Ying et al., 2012; Marchand et al., 2013; Sironi et al., 2006). Landfills can be particularly problematic in relation to odour nuisance (Che et al., 2013; Sakawi et al., 2017), and thus require specific protocols for odour control and measurement (Chemel et al., 2012; Lucernoni et al., 2016; Sarkar et al., 2003; Tansel et al., 2019).

As already mentioned, odours are currently subject to control and regulation in many countries. Dispersion models are the preferred approach to odour impact assessment in most of the regulations concerning odour around the world (Brancher et al., 2017). This is due to their ability to simulate odour dispersion from the emission sources into the atmosphere, and to calculate ambient odour concentration values in the simulation space-time domain. In some cases, odour regulations specify a minimum distance between the closest inhabited area and the location of possible odour-producing industrial or agricultural facilities (Brancher et al., 2019; Capelli et al., 2013). Minimum distances are typically calculated by applying dispersion models or using simplified mathematical formulas with specific coefficients derived from dispersion modelling (Schauberger et al., 2012a, 2012b). In other cases, regulations set acceptability standards in terms of the frequency with which a given odour concentration may be exceeded (Brancher et al., 2017; Capelli et al., 2013). 
Despite the great advantages of using dispersion models for odour impact assessment, there still are some critical aspects which require further study. One of the major open issues related to dispersion modelling is validation (Hayes 2006). This is particularly complex due to the difficulty of measuring odours in the environment (Capelli et al., 2013, 2018). Another important aspect is the uncertainty associated with dispersion models when applied to odour impact assessment studies (Brancher et al., 2019; Oettl et al., 2018).

The choice of a particular dispersion model will affect the resulting calculated impacts (Piringer et al., 2016), but also within each model there are different choices and parameters that may produce significant discrepancies in the model outputs. In general, dispersion models require three types of input data: emission data, topographic, and meteorological data of the site. The model combines these to produce an estimate of how pollutant emissions are diluted and diffused into the atmosphere. Each of the input datasets represent a possible source of uncertainty, as well as any other model-specific settings. In the case of odour dispersion modelling, the emission data input for the model is represented by the Odour Emission Rate (OER), expressed as units of odour emitted per unit time (Capelli et al., 2013). For characterizing the emissions source, the OER shall be put in relation with the geometrical and physical parameters of the source, which are also required by the dispersion model. For some types of sources, source term characterization and the estimation of the OER can be extremely complex. For instance, such cases include sources that have variable emissions over time, where it can be difficult to associate a specific OER to every hour of the simulation domain, or diffuse sources, for which the emitted air flow is diifult to estimate. Source term characterization is therefore typically considered to be the most critical step, and thus the major contributor to the overall uncertainty, in the implementation of an odour dispersion model (Capelli et al., 2014).

Characterization and implementation of a dispersion model is particularly problematic for landfill surfaces as a source. The determination of odour emissions from landfills is a complex and still hotly debated task (Lucernoni et al., 2017). Even under the assumption that the odour emission is associated mainly with the emission of landfill gas (LFG) escaping the collection system (Chemel et al., 2012; Saral et al., 2009), there are currently no universally accepted methodologies for evaluating the OER associated with this type of emission source (Lucernoni et al., 2017; Capelli and Sironi, 2018).

Another important element of uncertainty when modelling emissions from landfill surfaces is the geometrical implementation of the emission source in the model. In particular, the definition of the initial dimensions of the emission is critical in cases of large area sources.

This paper will discuss uncertainties in the application of dispersion modelling by referring to a specific case study regarding the assessment of the odour impact from a landfill with a surface of $55^{\prime} 000 \mathrm{~m} 2$. For the study, it was decided to apply the CALPUFF dispersion model, which is a commonly used model for regulatory purposes in Italy (Capelli et al., 2018; Ranzato et al., 2012).

More in detail, this paper will focus on two main sources of uncertainty. First, it will compare the different OER values obtained by using two different sampling methods, both of which are applicable for odour sampling on landfill surfaces (Capelli et al., 2018; Lucernoni et al., 2017). Second, it will investigate the effects of the so-called "initial vertical sigma" $\sigma Z, 0$, a parameter specifically required by the CALPUFF model when modelling area sources, related to the vertical dimension of the emission.

The present work, besides summarising some basic principles for the selection of the sampling method and the definition of the source geometry, will demonstrate the extent to which different choices regarding the model setting may affect its results, i.e. the simulated odour impact of the studied landfill.

\section{MATERIALS AND METHODS}

\subsection{Case study description}

The selected case study regards the odour impact assessment of a landfill with an emitting surface of $55^{\prime} 000$ $\mathrm{m} 2$. Since the principal aim of the study is to consider the influence of different choices in some critical parameters on the outputs, it was decided to limit the evaluations to the emissions from the closed landfill surface. This avoids introducing other variables and thus other possible sources of uncertainty. In this specific case, due to the large surface of the closed portion (55'000 m2) compared to the typical daily tipping area (about 1'000 m2), the closed portion of the landfill can reasonably be assumed to be the main source of odour emissions (Lucernoni et al., 2016).

The dispersion of the odour emissions from the landfill surface was evaluated using the CALPUFF model (Scire et al., 2000). CALPUFF is a multilayer, multispecies, nonsteady-state, puff dispersion model. It is currently the most commonly used dispersion model in Italy for odour impact assessment evaluations and regulatory purposes (Capelli et al., 2018; Ranzato et al., 2012).

The meteorological data used for the study is one year of 3D hourly data for 2015, processed using the WRF (Weather Research and Forecasting) model with a $1 \mathrm{~km}$ resolution relevant to the studied area. The meteorological domain and the simulation domain were set as the same, comprising an area of $4000 \mathrm{~m} \times 4000 \mathrm{~m}$, with a resolution of $100 \mathrm{~m}$, giving a total of 1600 horizontal cells. 10 cells were considered on the vertical plane, giving a total of 16000 cells for the study.

The emission data was derived from an olfactometric sampling carried out on the landfill surface, as described in the next paragraph.

\subsection{Odour sampling methods}

Up to now, no universally accepted methodology for sampling and assessing odour emissions from landfill surfaces has been established (Lucernoni et al., 2017; Capelli et al., 2018).

One common approach to assess both odour and landfill gas emissions from landfill surfaces involves the 
use of sampling hoods, such as static hoods, flux chambers, or wind tunnels (Di Trapani et al., 2013; Lucernoni et al., 2016, 2017; Rachor et al., 2013; Schroth et al., 2012). Wind tunnels are the "official" method foreseen by local Italian guidelines on odour impact assessment when conducting odour sampling on passive area sources (Capelli et al., 2018). The main difference between wind tunnels (WTs) and flux chambers (FCs) is the air flow rate at which the two systems are operated:

- In WTs the air flow is directional, whereas in FCs the inlet flux is mixed inside the hood;

- The typical air flow for WTs is about one order of magnitude higher than the air flow used in FCs.

Previous recent studies on the matter have proven that FCs provide a better representation of odour emissions from landfill surfaces (Lucernoni et al., 2017).

Since the aim of this study is to evaluate the effect of the most significant sources of uncertainty when assessing odour emissions from landfills, the choice of the sampling method was included in the aspects to be evaluated. Both a WT and a FC were used in this study, and the specific odour emission rate (SOER) values evaluated with the two methods were compared.

The WT used for this study has a base area of $0.125 \mathrm{~m}^{2}$, and is operated with an air flow of $40 \mathrm{~L} / \mathrm{min}$. The $\mathrm{FC}$ has the same base area as the WT (i.e. $0.125 \mathrm{~m}^{2}$ ) and is operated with an air flow of $4 \mathrm{~L} / \mathrm{min}$.

For both sampling methods, the SOER can be evaluated as follows:

SOER $=\left(c_{\text {od }} Q_{\text {air }}\right) / A_{\text {base }}$

Where SOER is the Specific Odour Emission Rate $\left(\mathrm{ou}_{\mathrm{E}} /\right.$ $\left.\mathrm{m}^{2} / \mathrm{s}\right)$, cod the measured odor concentration $\left(\mathrm{ou}_{\mathrm{E}} / \mathrm{m}^{3}\right), \mathrm{Q}_{\text {air }}$ the airflow rate inside the hood $\left(\mathrm{m}^{3} / \mathrm{s}\right)$ and $A_{\text {base }}$ the base area of the sampling hood $\left(\mathrm{m}^{2}\right)$. The SOER value is the parameter that is used as input for implementing area sources in dispersion models. Odour concentration was measured according to the EN 13725:2003.

For the collection of the odour samples, the landfill surface was divided into 9 sub-areas (Figure 1, left). One sample was collected at the centre of each sub-area.

\subsection{Definition of the initial vertical dispersion coef- ficient $\sigma_{\mathrm{z}, 0}$}

The CALPUFF model requires the definition of some specific dimensional parameters when characterizing an area source. Besides the source area and height, it is also necessary to define the so-called "initial vertical sigma", $\sigma_{z, 0^{\prime}}$ which is a measure of the initial vertical dimension of the emission.

Considerations on how to set this parameter can be found for Gaussian models (US EPA, 2004, 2011). The most common rule for the evaluation of $\sigma_{z, 0}$ is to set it equal to the vertical dimension of the source (i.e., the source height) divided by 2.15 , as suggested in Table 3-2 of the US EPA User's guide for the regulatory model AERMOD (US EPA, 2011). The 2.15 coefficient is derived from the Gaussian distribution of the pollutant concentration inside the plume. However, despite this simple rule, considerations for the correct setting of $\sigma_{z, 0}$ are not so simple.

As stated earlier, $\sigma_{z, 0}$ represents the initial vertical dimension of the plume (for a Gaussian model; in CALPUFF, $\sigma_{z, 0}$ represents the initial vertical dimension of the puff at the emission, but the considerations are similar). Therefore, as a general rule, $\sigma_{z, 0}$ is directly related to the source height. However, the source height is not the only parameter that may affect the initial vertical dimension of the plume. Especially for certain particular sources, as is also mentioned in the AERMOD User's Guide (US EPA, 2011). The guide specifies that in cases where the emission may be turbulently mixed near the source and therefore occupy some initial depth, the $\sigma_{z, 0}$ should be set so as to account for this initial vertical dimension of the emission. Unfortunately, it is not specified how to do that. Different methods
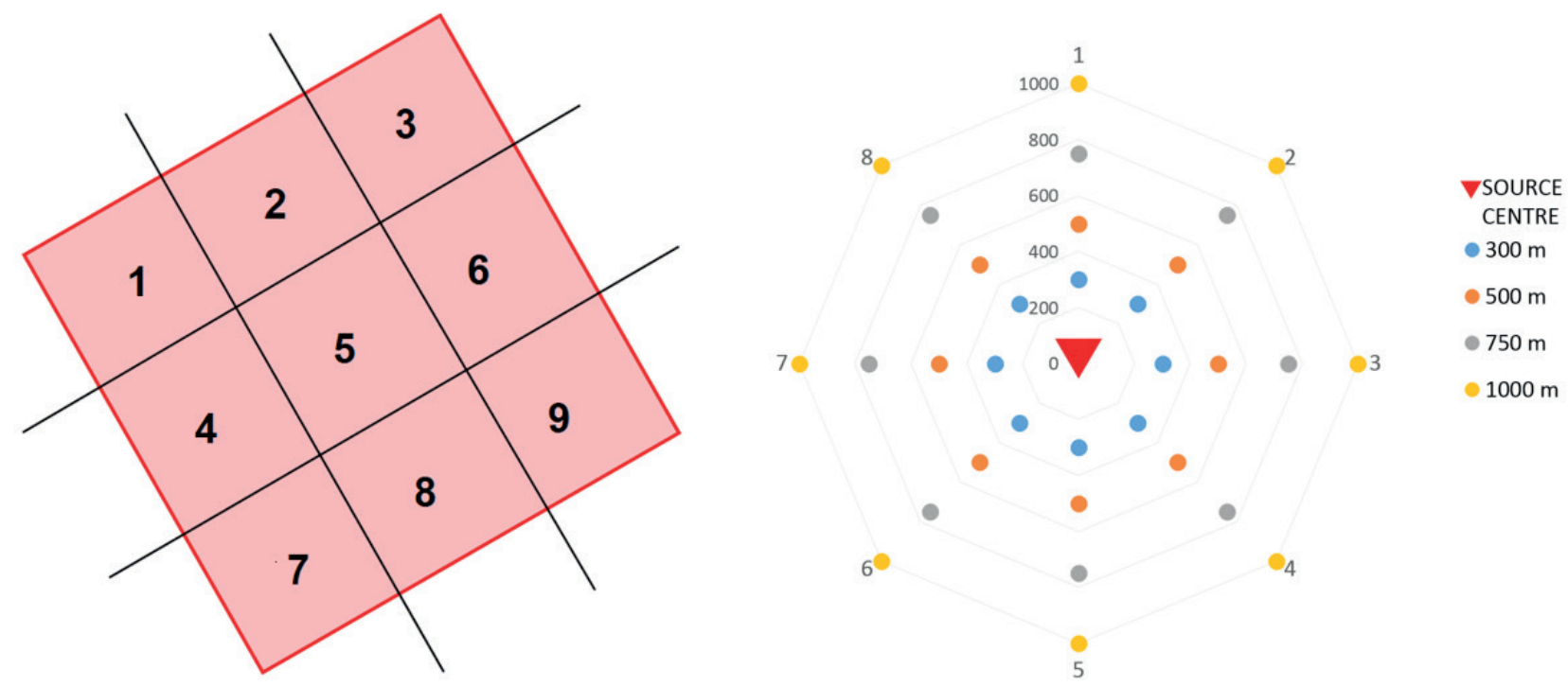

FIGURE 1: Division of the landfill into 9 sub-areas for olfactometric sampling (left) and location of the 32 discrete receptors selected for comparison of the model outputs obtained with different values of $\sigma_{z, 0}$ (right). 
for the calculation of $\sigma_{z, 0}$ can be found in the US EPA's Haul Road Workgroup final report to the Air Quality Modeling Group, though these are specifically related to the emissions from road transport. However, this document at least clearly shows that $\sigma_{z, 0}$ is not necessarily solely a function of the source height.

When it comes to area sources, $\sigma_{\mathrm{z}, 0}$ is the initial vertical dimension of the area source plume. Passive area sources, such as wastewater treatment tanks, are typically relatively small (compared to a landfill) and the emission occurs passively due to natural convection from the liquid surface to the atmosphere. In these cases, there is no reason to assume that turbulence plays an important role and cause the plume to have an increased initial dimension due to turbulent effects.

However, the case of landfills is different. First, landfills cannot be treated similarly to passive area sources because of the different mechanisms that regulate the emission from the surface to the atmosphere. There is a small - but not negligible - flux of gas that crosses the landfill body and is emitted into the atmosphere through the landfill surface. For this reason, landfills should be considered as "semi-passive" area sources. Second, landfills are typically very large area sources $\left(55^{\prime} 000 \mathrm{~m}^{2}\right.$ in the case study considered), characterized by an uneven surface - even considering the same parcel, the landfill surface can have different heights due to the presence of reliefs. Moreover, the landfill surface is typically scattered with "obstacles", such as LFG extraction wells. All these elements contribute to the presence of some degree of turbulence over the landfill surface. This means that the initial plume emitted by the landfill will have a height related to this turbulence. Finally, due to the large dimensions of the landfill, it can be reasonably supposed that the initial plume height $(\mathrm{PH})$ will also be related to the horizontal dimensions of the landfill. Higher plumes can be assumed to be emitted from very large landfills, where the turbulent contribution is higher, and the pollutants are carried along the landfill surface for its entire length to form the initial emission puff.

Because of the lack of precise rules for the evaluation of $\sigma_{z, 0}$ in such complex cases, and because of the complexity of the geometrical features of the landfill, it is not possible at this stage to establish one unique and unequivocal way for setting the value of $\sigma_{\mathrm{z} 0}$ in the model.

For these reasons, it was deemed useful to evaluate how the choice of different values of $\sigma_{z, 0}$, selected within a reasonable range, could affect the model results.

For this study the model was run using the following values of $\sigma_{z, 0}: 1,2,5,10,20$, and $30 \mathrm{~m}$. Besides comparing the different odour impact maps resulting from the model runs, further evaluations were made by comparing the odour concentrations calculated by the model on a set of selected receptors. A receptor nest was created by placing 8 receptors at distances of $300,500,750$ and $1000 \mathrm{~m}$ from the source centre, respectively, giving a total of 32 receptors, according to the scheme shown in Figure 1 (right).

\section{RESULTS AND DISCUSSION}

\subsection{Odour sampling on the landfill surface}

As already mentioned, olfactometric sampling was performed both with a Flux Chamber (FC) and a Wind Tunnel (WT). In order to compare the results obtained with the two methods, Table 1 reports the results of the olfactometric measurements carried out on the landfill site in terms of odour concentration (in $\mathrm{ou}_{\mathrm{E}} / \mathrm{m}^{3}$ ) and SOER, which was evaluated as described in section 2.2.

The lower odour concentration values were found in the samples collected using the wind tunnel. The higher operational airflow causes a higher dilution of the sample collected at the hood outlet. However, for the SOER, the opposite trend is observed: the SOER derived from the FC measurements is about three times lower than the SOER resulting from the wind tunnel measurements. This can be explained by the fact that the SOER is obtained by the product of the odour concentration and the airflow.

This in turn means that, depending on the sampling method adopted, the resulting emission data to be used as input for dispersion modelling - and consequently the resulting ambient concentrations - may vary by a factor of 3 . This clearly represents a significant source of uncertainty: the breach of acceptability criteria, or the determination of suitable separation distances, may be totally overturned by such an uncertainty factor.

As previously mentioned, there are recent studies re-

TABLE 1: Results of the olfactometric measurements of the odour samples collected over the landfill surface by means of a flux chamber (FC) and of a wind tunnel (WT).

\begin{tabular}{|c|c|c|c|c|}
\hline \multirow{2}{*}{ Sampling point } & FC & FC & WT & WT \\
\hline & Measured $\mathrm{c}_{\mathrm{od}}\left[\mathrm{ou}_{\mathrm{E}} / \mathrm{m}^{3}\right]$ & SOER $\left[\mathrm{ou}_{\mathrm{E}} / \mathrm{m}^{2} / \mathrm{s}\right]$ & Measured $\mathrm{c}_{\mathrm{od}}\left[\mathrm{ou}_{\mathrm{E}} / \mathrm{m}^{3}\right]$ & SOER $\left[\mathrm{ou}_{\mathrm{E}} / \mathrm{m}^{2} / \mathrm{s}\right]$ \\
\hline 1 & 750 & 0.40 & 140 & 0.75 \\
\hline 2 & 410 & 0.22 & 81 & 0.43 \\
\hline 3 & 270 & 0.14 & 60 & 0.32 \\
\hline 4 & 66 & 0.04 & 52 & 0.28 \\
\hline 5 & 1330 & 0.71 & 240 & 1.28 \\
\hline 6 & 840 & 0.45 & 310 & 1.65 \\
\hline 7 & 310 & 0.17 & 88 & 0.47 \\
\hline 8 & 860 & 0.46 & 280 & 1.49 \\
\hline 9 & 380 & 0.20 & 210 & 1.12 \\
\hline Geometric average & 440 & 0.23 & 134 & 0.71 \\
\hline
\end{tabular}


garding the estimation of odour emissions from landfill surfaces proving that WTs tend to overestimate emissions (Lucernoni et al., 2016, 2017). This overestimation is assumed to be due to the fact that odour concentration values measured using WTs are in some cases so low that they are likely to be attributable more to the odour of the landfill soil coverage than to the emission of LFG through the landfill surface (Lucernoni et al., 2016). Indeed, among the odour concentrations of the samples collected using the WT in this case, some values are so low that they are close to the lower detection limit for dynamic olfactometry (Lucernoni et al., 2016). This is less relevant for FC measurements, where the odour concentrations are considerably higher, and thus should prevent the interference of possible background odours.

\subsection{Evaluation of the effect of different values of $\sigma_{z, 0}$}

As described in section 2.3, the model was run by setting different values for $\sigma_{z, 0}$ in order to evaluate the influence of this parameter on the model outputs, i.e. on the simulated odour impact of the landfill on the surrounding territory.

The odour impact resulting from dispersion modelling was evaluated in terms of 98th percentile of the hourly peak odour concentration values simulated by the model on the receptor grid, in conformity with the prescriptions of the local regulations about odour pollution that are currently in force in Italy.

Figure 2 shows the maps of the 98th percentile hourly peak odour concentration values simulated by the model runs, obtained by setting different values for $\sigma_{z, 0}$, i.e. 1,5 , 10 and $30 \mathrm{~m}$, respectively. In order to allow for comparison, the same scale was used for the different maps.

It can be observed that the extent of the odour impact shrinks when $\sigma_{z, 0}$ increases: a higher initial dimension of the emission causes a better dispersion of the odour, and thus a lower resulting impact. This behaviour is particularly evident for the highest value of $\sigma_{z, 0}$ tested (i.e. $30 \mathrm{~m}$ ), whereas such differences are less pronounced in the maps resulting from the simulations with $\sigma_{z, 0}$ values of 1,5 and $10 \mathrm{~m}$. Indeed, the highest differences are observed close to the source, where the maximum odour concentrations modelled decrease significantly, whereas the shape and the extent of the iso-concentration lines at higher distance from the source look more similar between the different maps.

In order to better visualize the variations in the results relevant to the different conditions tested, the odour concentration values calculated punctually by the model on a set of different receptors, located at different distances from the source, were evaluated. The 98th hourly peak odour concentration values resulting for the different va-
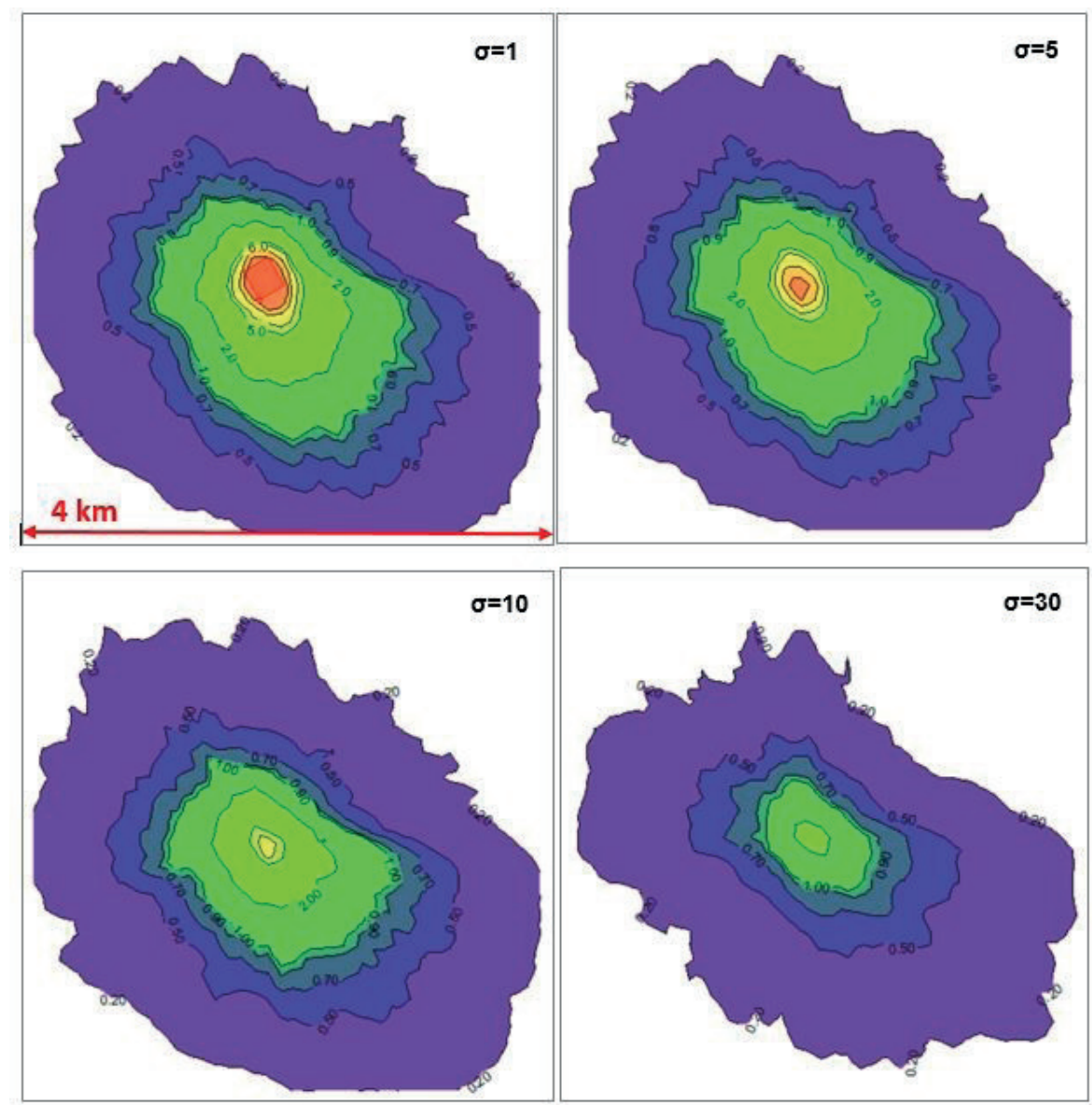

FIGURE 2: Maps of the 98th percentile of the hourly peak concentrations resulting from the model runs performed by setting the source $\sigma_{\mathrm{z}, 0}$ equal to $1,5,10$ and $30 \mathrm{~m}$, respectively. 
lues of $\sigma_{z 0}$ on the 32 receptors, selected as illustrated in section 2.3, are reported in Table 2.

The values reported in Table 2 reflect what is observed from the maps. In particular, odour concentrations higher than $5 \mathrm{ou}_{\mathrm{E}} / \mathrm{m}^{3}$, which is often taken as the reference value for acceptability criteria in Italian guidelines, are highlighted in red. When considering the receptors at 300 $\mathrm{m}$ from the source centre, by going from a $\sigma_{\mathrm{zo}}$ of $1 \mathrm{~m}$ to a $\sigma_{z, 0}$ of $30 \mathrm{~m}$, the resulting concentration on the receptor decreases by a factor $3-4$. This effect is less pronounced at higher distances from the source, where the decrease is about the half. Nonetheless, the variation factors in the model results obtained with different values of $\sigma_{z, 0}$ are quite high. Assuming that an acceptability criterion of $5 \mathrm{ou}_{\mathrm{E}} / \mathrm{m}^{3}$ at the closest receptors is fixed for the studied area, then it is clearly visible that the choice of the $\sigma_{\mathrm{z}, 0}$ value could cau- se the result to either stay below or exceed this limit. This consideration is particularly important, since, as stated in the introduction, dispersion models are often used for regulatory purposes.

\subsection{Discussion on the evaluation of the $\sigma_{z, 0}$ value}

Given that the setting of the $\sigma_{z, 0}$ for landfill sources represents an important degree of freedom in the model implementation, it is very important to analyse the variability of outputs derived from different possible - and reasonable - choices for this value. In this regard, it is important to highlight that, to the best of our knowledge, there is a lack of specific studies addressing this problem and discussing how to choose this parameter properly in order to obtain representative results.

TABLE 2: $98^{\text {th }}$ hourly peak odour concentration values calculated by the model for the different values of $\sigma_{z, 0}$ tested on the 32 discerete receptors selected at $300,500,750$, and $1000 \mathrm{~m}$ from the source centre, respectively.

\begin{tabular}{|c|c|c|c|c|c|c|}
\hline Receptor & $\sigma=1$ & $\sigma=2$ & $\sigma=5$ & $\sigma=10$ & $\sigma=20$ & $\sigma=30$ \\
\hline R1_300m & 4.67 & 4.38 & 3.79 & 2.79 & 1.52 & 1.27 \\
\hline $\mathrm{R} 2 \_300 \mathrm{~m}$ & 4.61 & 4.09 & 2.85 & 1.98 & 1.13 & 0.95 \\
\hline R3_300m & 5.25 & 5.02 & 4.27 & 2.80 & 1.83 & 1.52 \\
\hline R4_300m & 6.68 & 6.38 & 5.36 & 3.80 & 2.19 & 1.70 \\
\hline R5_300m & 5.99 & 5.65 & 4.74 & 3.22 & 1.77 & 1.25 \\
\hline R6_300m & 4.28 & 4.04 & 3.37 & 2.43 & 1.32 & 0.87 \\
\hline R7_300m & 4.44 & 4.19 & 3.53 & 2.60 & 1.59 & 0.96 \\
\hline R8_300m & 3.73 & 3.58 & 3.14 & 2.45 & 1.45 & 1.03 \\
\hline R1_500m & 1.78 & 1.75 & 1.63 & 1.29 & 0.95 & 0.82 \\
\hline R2_500m & 1.24 & 1.17 & 1.11 & 0.81 & 0.63 & 0.58 \\
\hline R3_500m & 2.69 & 2.63 & 2.35 & 2.01 & 1.32 & 0.98 \\
\hline R4_500m & 4.07 & 3.81 & 3.36 & 2.29 & 1.48 & 1.07 \\
\hline R5_500m & 3.35 & 3.18 & 2.76 & 1.92 & 1.03 & 0.76 \\
\hline R6_500m & 1.99 & 1.94 & 1.68 & 1.29 & 0.77 & 0.54 \\
\hline R7_500m & 1.98 & 1.94 & 1.79 & 1.48 & 1.11 & 0.66 \\
\hline R8_500m & 1.63 & 1.61 & 1.53 & 1.29 & 0.86 & 0.83 \\
\hline R1_750m & 0.69 & 0.75 & 0.66 & 0.62 & 0.50 & 0.44 \\
\hline R2_750m & 0.75 & 0.74 & 0.71 & 0.58 & 0.47 & 0.38 \\
\hline R3_750m & 1.40 & 1.39 & 1.28 & 1.16 & 0.78 & 0.71 \\
\hline R4_750m & 2.10 & 2.07 & 1.95 & 1.47 & 1.03 & 0.82 \\
\hline R5_750m & 1.89 & 1.86 & 1.57 & 1.09 & 0.74 & 0.50 \\
\hline R6_750m & 1.06 & 1.04 & 0.96 & 0.75 & 0.50 & 0.41 \\
\hline R7_750m & 1.14 & 1.13 & 1.05 & 0.95 & 0.64 & 0.44 \\
\hline R8_750m & 0.96 & 0.95 & 0.91 & 0.77 & 0.58 & 0.55 \\
\hline R1_1km & 0.49 & 0.56 & 0.47 & 0.40 & 0.37 & 0.33 \\
\hline R2_1km & 0.50 & 0.46 & 0.45 & 0.35 & 0.23 & 0.20 \\
\hline R3_1km & 1.05 & 1.04 & 0.98 & 0.89 & 0.71 & 0.62 \\
\hline R4_1km & 1.37 & 1.36 & 1.29 & 0.99 & 0.79 & 0.60 \\
\hline R5_1km & 1.27 & 1.25 & 1.12 & 0.90 & 0.55 & 0.40 \\
\hline R6_1km & 1.73 & 1.68 & 1.44 & 1.01 & 0.68 & 0.52 \\
\hline R7_1km & 0.73 & 0.72 & 0.65 & 0.62 & 0.52 & 0.36 \\
\hline R8_1km & 0.61 & 0.61 & 0.60 & 0.54 & 0.46 & 0.43 \\
\hline
\end{tabular}


To be able to recommend a certain value, validation in the field would be necessary in order to evaluate the model capability to predict experimental observations. For this purpose, field inspections for the determination of the odour plume extensions represent an interesting opportunity (Capelli et al., 2013; Capelli and Sironi, 2018). Another way of verifying the predictions of dispersion models would be to carry out field monitoring with electronic noses (Capelli et al., 2013). However, model validation was not foreseen in this study because of the high costs involved. Indeed, in the case of odour, the development of an ad hoc trial to validate model predictions is a complicated task (Capelli et al., 2013).

In general, it would be extremely useful to integrate validation efforts with a more theoretical approach, based on the study of atmospheric turbulence over large area sources. For this purpose, further studies will be conducted in the future dealing specifically with the influence that turbulence has on emissions, thus providing more precise indications on ways to select appropriate values for $\sigma_{z, 0}$.

Another way to evaluate how to establish an appropriate value for $\sigma_{z, 0}$ might be to compare with results from other dispersion models which have a lower degree of uncertainty and do not require the definition of $\sigma_{z, 0^{\circ}}$ In this case, the optimal $\sigma_{z, 0}$ would be the one that provides results in closer agreement with the other models. However, by definition, air quality models can only approximate atmospheric processes and many assumptions are required to describe real phenomena in mathematical equations (Moussiopoulos et al., 1996). Therefore, agreement with other dispersion models does not necessarily ensure representative results.

It is worth highlighting that the initial vertical dispersion coefficient is a parameter specifically required by the CALPUFF model in cases of area sources. If the landfill is implemented as a point source, the model automatically sets a default value for the $\sigma_{z, 0}$ equal to the height of the emission source divided by a factor of 2.15. In that case, the choice of $\sigma_{z, 0}$ wouldn't be an issue. Conversely, when dealing with point sources, a proper value for the vertical rise velocity, which is not required in cases of area sources, has to be defined. In the case of a landfill, the estimation of the rise velocity could be done based on the evaluation of the landfill gas flux from the landfill surface. However, due to the large dimensions that are typical of landfills, their approximation as point sources could also be inappropriate. .

\section{CONCLUSIONS}

Dispersion models are currently the most common method for assessing odour impacts for regulatory purposes. For this reason, it is important to analyse the differences in the results, which can be produced by making different modelling choices.

The choice of method to obtain the required olfactometric data to characterize the emissions from the landfill surface is particularly critical. Wind tunnels are the sampling method foreseen by Italian regulations on the matter, however, previous studies have proven such systems to overestimate emissions. In this study, we found that wind tunnels produce odour emission rate values that are three times higher than those obtained with flux chambers. This is reflected in the model outputs resulting in concentrations at receptors that are three times higher.

Another critical parameter for area source characterization in the CALPUFF model is the so called "initial vertical sigma" $\sigma_{z, 0}$. Given that the definition of the $\sigma_{z, 0}$ for landfill surfaces represents an important degree of freedom when implementing the source term in CALPUFF, it is important to be aware of the variability of results that derives from possible - and reasonable - choices for this value. The sensitivity analysis conducted relevant to the proposed case study, involving a landfill with a surface of $55^{\prime} 000 \mathrm{~m}^{2}$, shows that, for $\sigma_{z, 0}$ values ranging from $1 \mathrm{~m}$ to $30 \mathrm{~m}$, modelled concentrations at receptors may vary by almost a factor 4 at $300 \mathrm{~m}$ from the source and by a factor 2 at a distance of $1 \mathrm{~km}$.

This high variability should not cause distrust in the method, but should emphasize the importance of properly implementing the model. To do that, it is necessary to analyse the physical and chemical mechanisms related to the emission of odours from the studied sources, in order to choose the most appropriate sampling strategy and define the initial dimensions of the emitted plume or puff within a narrow range. Especially in the case of verification of compliance to acceptability criteria, it is important that odour dispersion modelling studies are carried out by experts with appropriate knowledge and understanding of the odour emissions under investigation.

\section{REFERENCES}

Brancher, M., Griffiths, K. D., Franco, D., \& de Melo Lisboa, H., 2017. A review of odour impact criteria in selected countries around the world. Chemosphere 168, 1531-1570. https://doi.org/10.1016/j. chemosphere.2016.11.160

Brancher, M., Piringer, M., Grauer, A. F., \& Schauberger, G., 2019. Do odour impact criteria of different jurisdictions ensure analogous separation distances for an equivalent level of protection? J. Environ. Manage. 240, 394-403. https://doi.org/10.1016/j. jenvman.2019.03.102

Capelli, L., Sironi, S., Del Rosso, R., Bianchi, G., \& Davoli, E., 2012. OIfactory and toxic impact of industrial odour emissions. Water Sci. Technol. 66(7), 1399-1406. https://doi.org/10.2166/wst.2012.352

Capelli, L., Sironi, S., Del Rosso, R., \& Guillot, J. M., 2013. Measuring odours in the environment vs. dispersion modelling: A review. Atmos. Environ. 79, 731-743. https://doi.org/10.1016/j.atmosenv.2013.07.029

Capelli, L., Dentoni, L., Sironi, S., \& Del Rosso, R., 2014. The need for electronic noses for environmental odour exposure assessment. Water Sci. Technol. 69(1), 135-141. https://doi.org/10.2166/ wst.2013.544

Capelli, L., \& Sironi, S., 2018. Combination of field inspection and dispersion modelling to estimate odour emissions from an Italian landfill. Atmos. Environ. 191, 273-290. https://doi.org/10.1016/j. atmosenv.2018.08.007

Che, Y., Yang, K., Jin, Y., Zhang, W., Shang, Z., \& Tai, J., 2013. Residents' concerns and attitudes toward a municipal solid waste landfill: integrating a questionnaire survey and GIS techniques. Environ. Monit. Assess. 185(12), 10001-10013.

Chemel, C., Riesenmey, C., Batton-Hubert, M., \& Vaillant, H., 2012. Odour-impact assessment around a landfill site from weathertype classification, complaint inventory and numerical simulation. J. Environ. Manage. 93(1), 85-94. https://doi.org/10.1016/j. jenvman.2011.08.016

Di Trapani, D., Di Bella, G. \& Viviani, G., 2013. Uncontrolled methane emissions from a MSW landfill surface: Influence of landfill features and side slopes. Waste Manage. 33, 2108-2115. https://doi. org/10.1016/j.wasman.2013.01.032 
Hayes, E. T., Curran, T. P., \& Dodd, V. A., 2006. A dispersion modelling approach to determine the odour impact of intensive poultry production units in Ireland. Bioresource Technol. 97(15), 1773-1779. https://doi.org/10.1016/j.biortech.2005.09.019

Henshaw, P., Nicell, J., \& Sikdar, A., 2006. Parameters for the assessment of odour impacts on communities. Atmos Environ. 40, 1016-1029. https://doi.org/10.1016/j.atmosenv.2005.11.014

Lucernoni, F., Tapparo, F., Capelli, L., \& Sironi, S., 2016. Evaluation of an Odour Emission Factor (OEF) to estimate odour emissions from landfill surfaces. Atmos Environ. 144, 87-99. https://doi. org/10.1016/j.atmosenv.2016.08.064

Lucernoni, F., Capelli, L., \& Sironi, S., 2017. Comparison of different approaches for the estimation of odour emissions from landfil surfaces. Waste Manage. 63, 345-353. https://doi.org/10.1016/j. wasman.2016.09.041

Marchand, M., Aissani, L., Mallard, P., Béline, F., \& Réveret, J. P., 2013. Odour and life cycle assessment (LCA) in waste management: a local assessment proposal. Waste Biomass Valori. 4(3), 607-617. https://doi.org/10.1007/s12649-012-9173-z

Moussiopoulos, N., Berge, E., Bøhler, T., de Leeuw, F., Grønskei, K. E., Mylona, S., Tombrou, M., 1996. Ambient air quality, pollutant dispersion and transport models. European Topic Centre on Air Quality.

Oettl, D., Kropsch, M., \& Mandl, M., 2018. Odour assessment in the vicinity of a pig-fatting farm using field inspections (EN 16841-1) and dispersion modelling. Atmos. Environ. 181, 54-60. https://doi. org/10.1016/j.atmosenv.2018.03.029

Piringer, M., Knauder, W., Petz, E., \& Schauberger, G., 2016. Factors influencing separation distances against odour annoyance calculated by Gaussian and Lagrangian dispersion models. Atmos. Environ. 140, 69-83. https://doi.org/10.1016/j.atmosenv.2016.05.056

Rachor, I. M., Gebert, J., Gröngröft, A., \& Pfeiffer, E. M., 2013. Variability of methane emissions from an old landfill over different timescales. Eur. J. Soil. Sci. 64(1), 16-26. https://doi.org/10.1111/ ejss. 12004

Ranzato, L., Barausse, A., Mantovani, A., Pittarello, A., Benzo, M., \& Palmeri, L., 2012. A comparison of methods for the assessment of odor impacts on air quality: Field inspection (VDI 3940) and the air dispersion model CALPUFF. Atmos. Environ. 61, 570-579. https:// doi.org/10.1016/j.atmosenv.2012.08.009

Sakawi, Z., SA, S. M., Jaafar, O., \& Mahmud, M., 2017. Community perception of odour pollution from landfills. Geografia Malays. J. Soc. Space 7(3).

Saral, A., Demir, S., \& Yıldız, Ş., 2009. Assessment of odorous VOCs released from a main MSW landfill site in Istanbul-Turkey via a modelling approach. J. Hazard. Mater. 168(1), 338-345. https://doi. org/10.1016/j.jhazmat.2009.02.043
Sarkar, U., Longhurst, P. J., \& Hobbs, S. E., 2003. Community modelling: a tool for correlating estimates of exposure with perception of odour from municipal solid waste (MSW) landfills. J. Environ. Manage. 68(2), 133-140. https://doi.org/10.1016/S0301-4797(03)00027-6

Schauberger, G., Piringer, M., Jovanovic, O., \& Petz, E., 2012a. A new empirical model to calculate separation distances between livestock buildings and residential areas applied to the Austrian guideline to avoid odour nuisance. Atmos Environ. 47, 341-347. https:// doi.org/10.1016/j.atmosenv.2011.10.056

Schauberger, G., Schmitzer, R., Kamp, M., Sowa, A., Koch, R., Eckhof, W., ... \& Hartung, E., 2012b. Empirical model derived from dispersion calculations to determine separation distances between livestock buildings and residential areas to avoid odour nuisance. Atmos Environ. 46, 508-515. https://doi.org/10.1016/j.atmosenv.2011.08.025

Schroth, M. H., Eugster, W., Gómez, K. E., Gonzalez-Gil, G., Niklaus, P. A., \& Oester, P., 2012. Above-and below-ground methane fluxes and methanotrophic activity in a landfill-cover soil. Waste Manage. 32(5), 879-889. https://doi.org/10.1016/j.wasman.2011.11.003

Scire, J. S., Strimaitis, D. G., \& Yamartino, R. J., 2000. A user's guide for the CALPUFF dispersion model. Earth Tech, Inc. Concord, MA, 10.

Sironi, S., Capelli, L., Céntola, P, Del Rosso, R. \& II Grande, M., 2006 Odour emission factors for the prediction of odour emissions from plants for the mechanical and biological treatment of MSW. Atmos Environ. 40(39), 7632-7643. https://doi.org/10.1016/j.atmosenv.2006.06.052

Sucker, K., Both, R., \& Winneke, G, 2001. Adverse effects of environmental odours: reviewing studies on annoyance responses and symptom reporting. Water Sci. Technol. 44(9), 43-51. https://doi. org/10.2166/wst.2001.0505

Tansel, B., \& Inanloo, B., 2019. Odor impact zones around landfills: Delineation based on atmospheric conditions and land use characteristics. Waste Manage. 88, 39-47. https://doi.org/10.1016/j. wasman.2019.03.028

US Environmental Protection Agency, 2004. User's guide for the AMS/ EPA regulatory model-AERMOD.

US Environmental Protection Agency, 2011. Haul Road Workgroup final report to the Air Quality Modeling Group.

Ying, D., Chuanyu, C., Bin, H., Yueen, X., Xuejuan, Z., Yingxu, C., Weixiang W., 2012. Characterization and control of odorous gases at a landfill site: A case study in Hangzhou, China. Waste Manage. 32, 317 - 326. https://doi.org/10.1016/j.wasman.2011.07.016

Zhao, Y., Lu, W., \& Wang, H., 2015. Volatile trace compounds released from municipal solid waste at the transfer stage: evaluation of environmental impacts and odour pollution. J. Hazard. Mater. 300, 695-701. https://doi.org/10.1016/j.jhazmat.2015.07.081 